\title{
Developed Power Quality Monitor Used for Shunt Active Power Filter Studies
}

\author{
J. G. Pinto ${ }^{1}$, R. Pregitzer ${ }^{1}$, Luís F. C. Monteiro ${ }^{1}$ José Batista $^{2}$, João L. Afonso ${ }^{1}$ \\ ${ }^{1}$ Department of Industrial Electronics \\ University of Minho \\ Campus de Azurém, 4800-058 Guimarães, Portugal \\ Phone:+351 253510190 \\ ${ }^{2}$ Department of Electronics \\ Polytechnical Institute of Bragança \\ Campus de Sta. Apolónia 5301-857 Bragança, Portugal \\ Phone: +351273 303000
}

E-mail: gpinto@dei.uminho.pt,rpregitzer@dei.uminho.pt, lmonteiro@dei.uminho.pt,jbatista@ipb.pt, jla@dei.uminho.pt

\begin{abstract}
This paper presents a developed Power Quality Monitor used to perform studies in a prototype of a three-phase four wire Shunt Active Power Filter. In the developed equipment, the voltage measurements are made through Hall-effect sensors and for the current measurements flexible Rogowski Coil sensors are used. A conditioning circuit is used to interface the data from the sensors to a standard data acquisition board. The monitoring software was developed in LabVIEW ${ }^{\mathrm{TM}}$ that allows the applications to run on Windows in a regular PC. The developed system acquires the data continuously, and stores the desired events in the hard disk.

In the case described in this paper, the Power Quality Monitor allows to simultaneously measure the three phase voltages of the power system and four currents, which can be from the source, from the load or from the output of the Shunt Active Filter.
\end{abstract}

\section{Keywords}

Power Quality Monitor, Power Quality Analyzer, Shunt Active Filter, p-q Theory, Digital Control, Harmonics Compensation.

\section{Introduction}

The increasing use of power converters and other nonlinear loads makes Power Quality a key issue for the producers, distributors and consumers. The lack of Power Quality can cause several problems to the consumers that require high levels of Power Quality for their industrial processes or home use. The IEEE 1159 Standard classifies various electromagnetic phenomena in power systems voltage (which are related to Power Quality problems), namely: impulses, oscillations, sags, swells, interruptions, undervoltages, overvoltages, dc offset, harmonics, interharmonics, notches, noise, flicker, and frequency variation [1]. Because of these and other problems, the issue of the Power Quality delivered to the end consumers is, more than ever, an object of great concern. International standards concerning electrical Power Quality (IEEE-519, IEC 61000, EN 50160 [2], among others) impose that electrical equipments and facilities should not produce harmonic contents greater than specified values, and also specify distortion limits to the supply voltage.

Power quality studies are the necessary first step in order to determine the nature of the existing problems at a given installation, so that measures can be taken to solve, or at least to reduce these problems to acceptable levels [3].

Because many of the commercially available equipments are either too expensive, or have too many limitations, it was decided to develop a low-cost Power Quality monitor, with a prototype (Fig. 1) cost of about $3.000 €$, that could be an alternative to the equipment existing in the market.

In Fig 1 it is possible to see a photo of the developed Power Quality Monitor

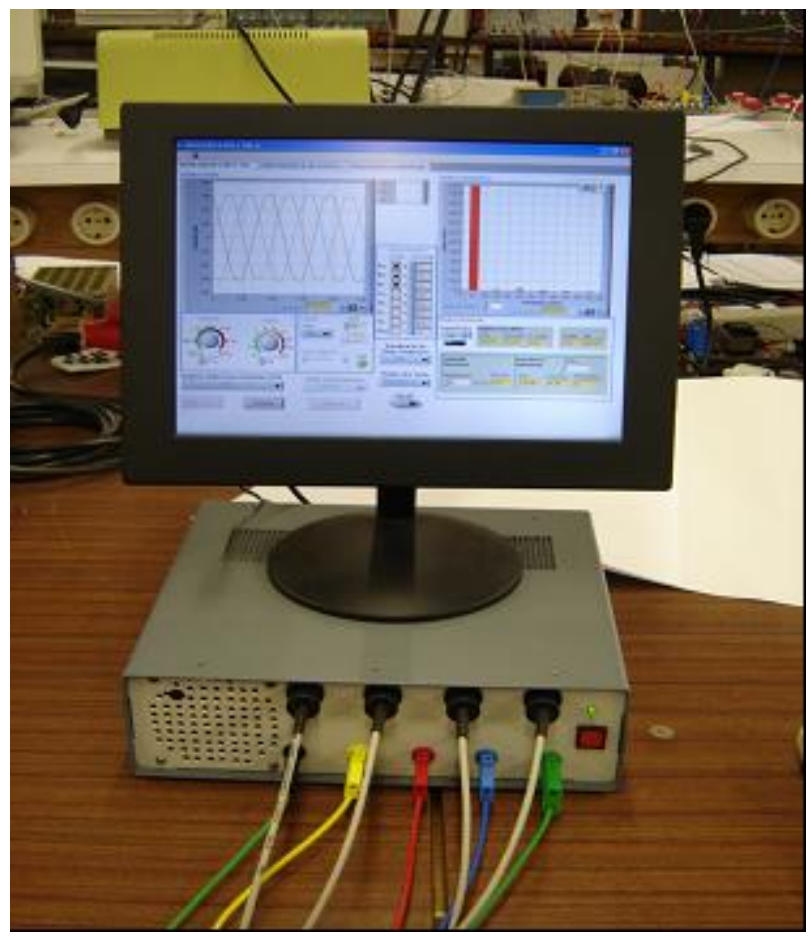

Fig. 1. Power Quality Monitor. 


\section{Characteristics of the Power Quality Monitor}

The developed Power Quality Monitor consists of a Personal Computer with a mini ITX motherboard (VIA $C 3^{\mathrm{TM}} / V I A E d e n^{\mathrm{TM}} E B G A$ processor, running Windows XP), a data acquisition card (National Instruments NI-6220), and a custom made hardware module [4]. The card can read 8 analogue signals in differential mode, with a 16 bit resolution and a $250 \mathrm{ksps}$ sampling rate, as well as $24 \mathrm{I} / \mathrm{O}$ digital lines.

To read the voltages and currents of the electrical systems a hardware module was developed, comprising four voltage sensors (Hall effect LEM LV 25-P) with $10 \mathrm{kHz}$ bandwidth and four current sensors (flexible Rogowski Coil LEM-FLEX ${ }^{\circledR}$ - RR3020) with $10 \mathrm{~Hz}$ to $20 \mathrm{kHz}$ bandwidth (Fig. 2). The current sensors offer the possibility of choosing from three scales $(30 \mathrm{~A}, 300 \mathrm{~A}$ and 3,000 A), and it is not necessary to disconnect the electrical system that will be monitored in order to use them. The measured signals are the three phase-to-neutral voltages and the neutral-to-ground voltage, as well as the three phase and the neutral currents (comprising a total of 8 electrical signals).

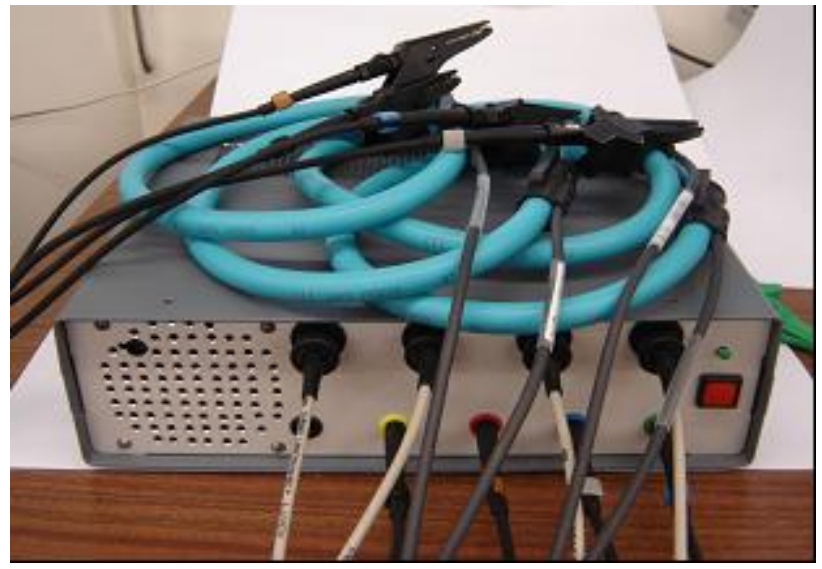

Fig. 2. Voltage terminals and current sensors connected to the Power Quality Monitor.

The Power Quality Monitor software applications were developed by the authors using the graphical programming tool LabVIEW ${ }^{\mathrm{TM}}$ and are briefly described below.

\section{A. Application "Scope and THD"}

With this application the signals of the 8 isolated channels ( 4 for voltages and 4 for currents) can be visualized simultaneously, with a sampling rate of 25 $\mathrm{kHz}$ per channel. The application also includes the normal functions of a standard scope, like the time base, vertical amplifier gain, trigger setup (slope, level and source), and readouts (signal frequency, True RMS values, DC values, peak to peak values, etc). It is also possible to calculate the THD and all of the individual harmonics (frequency, amplitude, and phase angle).

\section{B. Application "Events $P Q$ (Power Quality)"}

This application acquires, the three phase-to-neutral voltages $\left(v_{a n}, v_{b n}\right.$ and $\left.v_{c n}\right)$, the neutral-to-ground voltage $\left(v_{n g}\right)$, the three phase currents $\left(i_{a}, i_{b}\right.$ and $\left.i_{c}\right)$ and the neutral current $\left(i_{n}\right)$. Simultaneously, all the necessary procedures to create strip charts, to detect sags and swells, and wave shape type anomalies, are executed every cycle, and all the important information is saved to a file.

\section{Application "Classical Values"}

This application calculates various parameters used on the analysis of an electrical system: True RMS values and phase angles for each of the acquired signals, phase impedances, voltage and current unbalance, total and displacement power factor, power (active, reactive, harmonic and apparent), active energy (kWh) and "reactive" energy (kVArh). A phasor diagram of the voltages and currents is also plotted in real time using only the fundamental component of each of the signals.

\section{Application " $p-q$ Theory"}

This application presents the values produced by the "Theory of the Instantaneous Reactive Power" ( $p-q$ Theory). This theory consists basically in an algebraic transformation (Clarke transformation) of the three-phase voltages and currents in $a-b-c$ coordinates into $\alpha-\beta-0$ coordinates, followed by the calculation of the $\mathrm{p}-\mathrm{q}$ theory instantaneous power components. The knowledge of these components can be useful to analyze a three-phase power system, since they allow viewing some of the Power Quality problems under a different point of view. This application can also calculate the values of currents and instantaneous power that the source would have to supply if a shunt active power filter was used to compensate for harmonics, reactive power and zero sequence current. The signals can be shown in $a-b-c$ or $\alpha$ $\beta-0$ coordinates and presented through a window showed in Fig. 3.

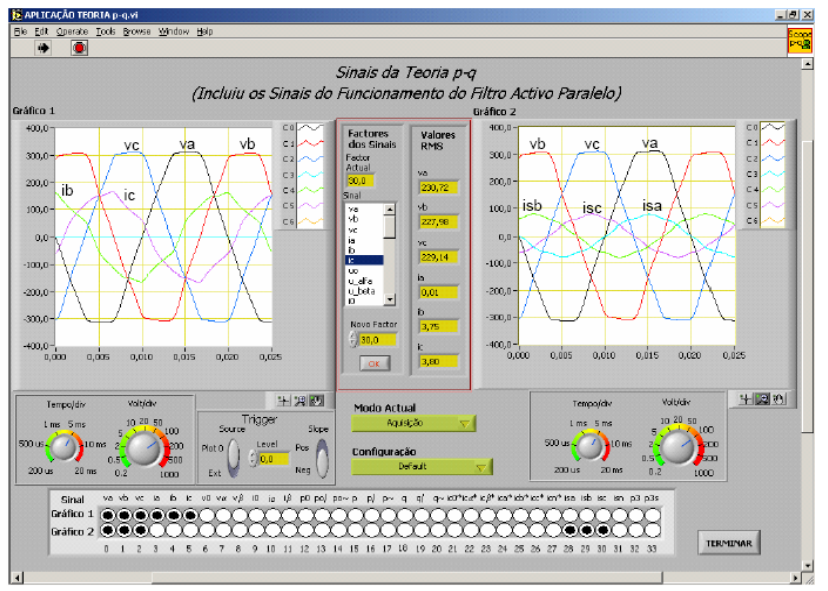

Fig. 3. The "p-q Theory" application display. 


\section{Shunt Active Power Filter}

The Shunt Active Power Filter analyzed in this paper was designed for 3-phase 4-wire systems and is capable of compensating current harmonics, current unbalance and power factor in 3-phase 4-wire electric systems. Fig. 4 shows the laboratory prototype of this active filter.

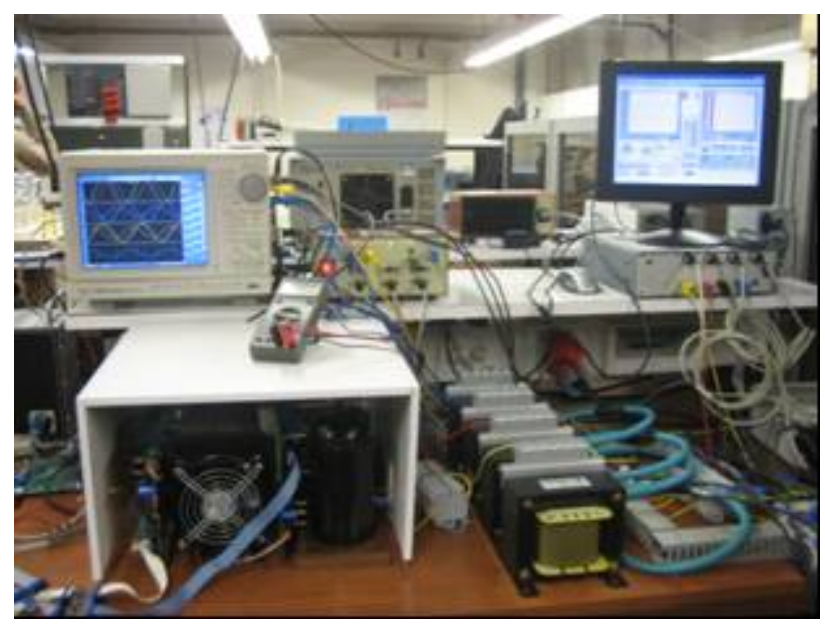

Fig. 4. Implemented laboratory prototype of the Shunt Active Power Filter with Power Quality Monitor.

The control system is based on the $\mathrm{p}-\mathrm{q}$ Theory, and uses the Sinusoidal Currents Strategy [5]. This control strategy requires a positive sequence detector for the system voltages in order to correctly calculate the reference currents. This controller was implemented on a TMS320F2812 DSP from Texas Instruments and the $p-q$ Theory was adapted in order to contain only fixed-point calculations that require little computational effort, therefore no square roots were used and the number of divisions was minimized. Fig. 5 shows the simplified block diagram of the controller. The controller requires the load currents, $i_{a}, i_{b}, i_{c}$, the system voltages, $v_{a}, v_{b}, v_{c}$, as well as the dc-link voltage $V_{d c}$. The output variables are the reference currents $i_{f a}{ }^{*}, i_{f b}{ }^{*}, i_{f c}{ }^{*}$ and $i_{f n}{ }^{*}$. More detailed information about this controller can be found in [6].

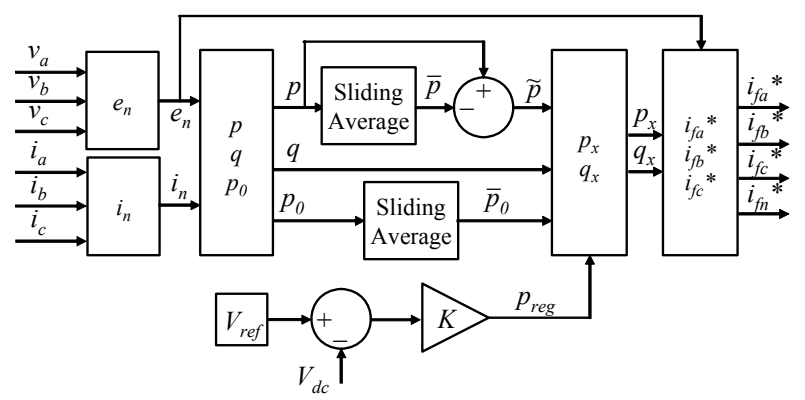

Fig. 5. Block diagram of the digital controller.

The modulation technique used to drive the IGBTs was the Periodic Sampling, which is a simple method that does not work with a fixed switching frequency, but limits its maximum value [7].

The Shunt Active Filter prototype presented in this work uses a standard 2-level Voltage Source Inverter implemented with Mitsubishi PM25RSB120 IGBT modules. In order to minimize the noise injected by the inverter on the electrical system, it is used an inductor $(L)$ to interface each of the inverter legs with the phases and neutral of the electrical system. Fig. 6 shows the implemented inverter, not including the snubber circuits used for each IGBT.

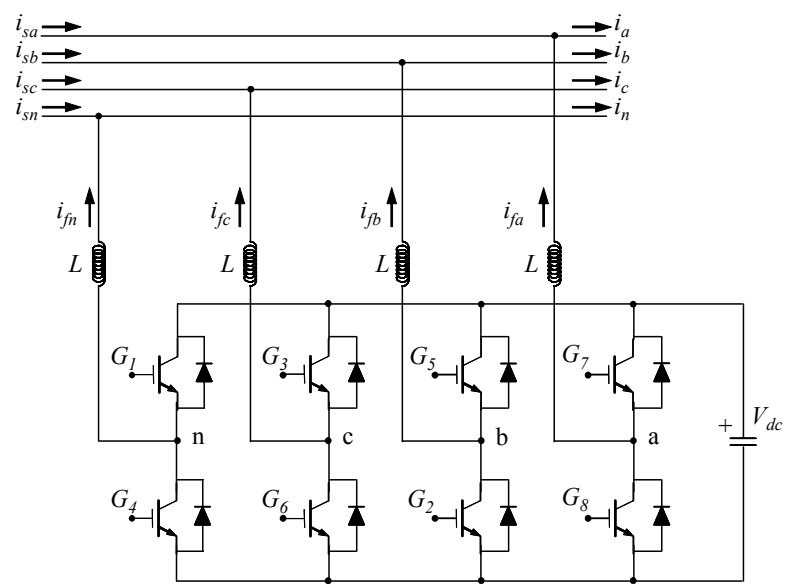

Fig. 6. Implemented Shunt Active Filter inverter.

Table I summarizes some of the most important characteristics of the developed Shunt Active Filter.

TABLE I. - Parameters of the Shunt Active Filter

\begin{tabular}{|l|l|}
\hline Digital sampling frequency & $32 \mathrm{kHz}$ \\
\hline dc-link capacitor $(C)$ & $2350 \mu \mathrm{F}$ \\
\hline Inductor $(L)$ series characteristics & $5 \mathrm{mH} / 0.9 \Omega$ \\
\hline Reference dc voltage $\left(V_{d c}\right)$ & $250 \mathrm{~V}$ \\
\hline Maximum switching frequency & $16 \mathrm{kHz}$ \\
\hline
\end{tabular}

\section{Power Quality Studies in a Shunt Active Power Filter}

The Power Quality Monitor will be used to show the characteristics of the currents before and after the installation of the Shunt Active Filter. It will make possible to see if the Power Quality has improved, and it could also be used to calculate potential savings thanks to a reduction of the losses at the power system.

Another advantage of this Power Quality Monitor is the fact that it allows the users to check if the active filter is injecting the correct currents in the power system by using the application " $p-q$ Theory". This application also helps with the determination/optimization of some control parameters of the Shunt Active Filter.

The prototype was evaluated on a 3-phase, 4-wire, $75 \mathrm{~V}$ (phase to neutral), $50 \mathrm{~Hz}$ electrical system with two different load configurations. The Monitoring System is used to measure the system voltages and source currents in order to analyze the behavior of the electric system before and after the connection of the Shunt Active Filter. The first load used to test the active filter consists in a three-phase diode rectifier with a RL load on the dc side, and in three inductors connected in wye configuration. Fig. 7 shows the configuration of the electric system for the first load. There is practically no current unbalance in this first test, only harmonic current distortion and an inductive power factor. 


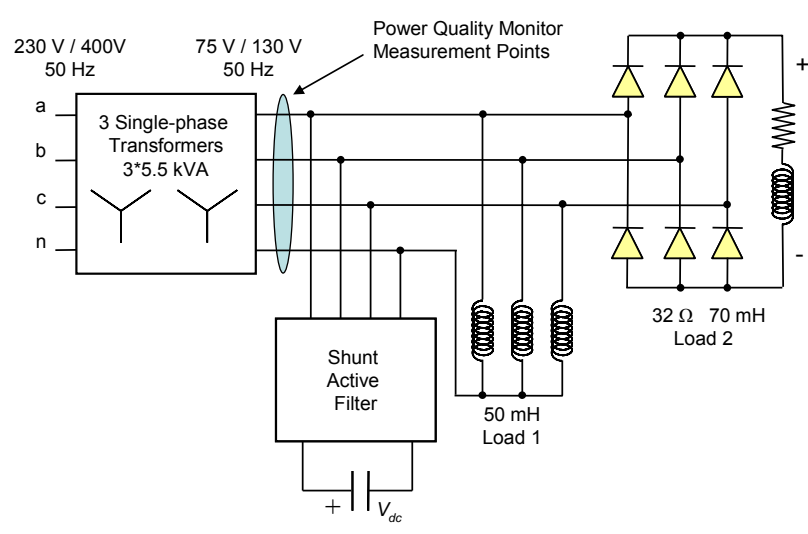

Fig. 7. First configuration of the electric system.

Fig. 8 shows the waveforms of the voltages and currents obtained with the Power Quality Monitor. Figures 9 and 10 show the phasor diagrams of the voltages and the currents, respectively. These figures also present the voltage or current amplitudes, phase angles, and the percentage value of the unbalance factor, for voltages and currents, which is named "Factor de Desequilíbrio (\%):” (written in Portuguese).

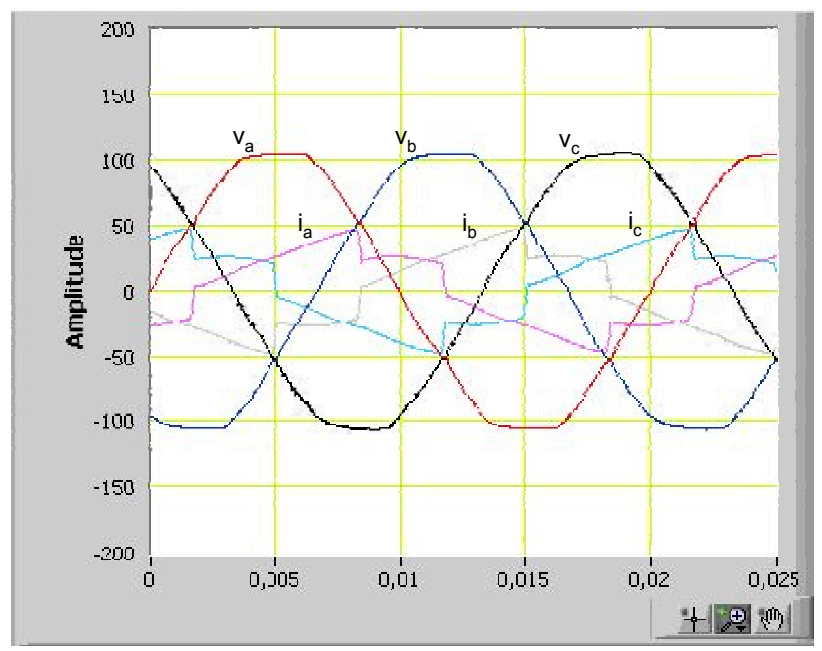

Fig. 8. System voltages and source currents waveforms when the Shunt Active Power Filter is not connected.

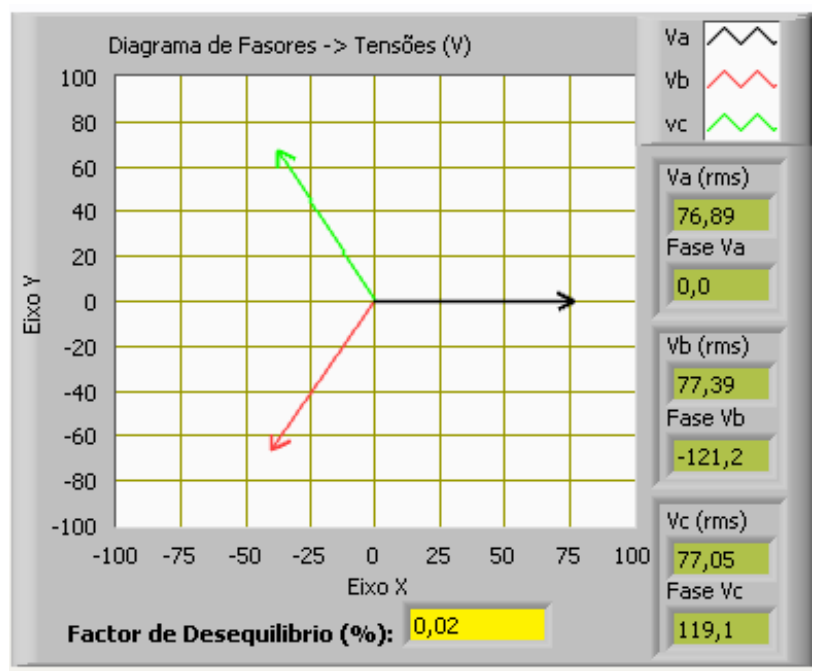

Fig. 9. Phasor diagram of the system voltages.

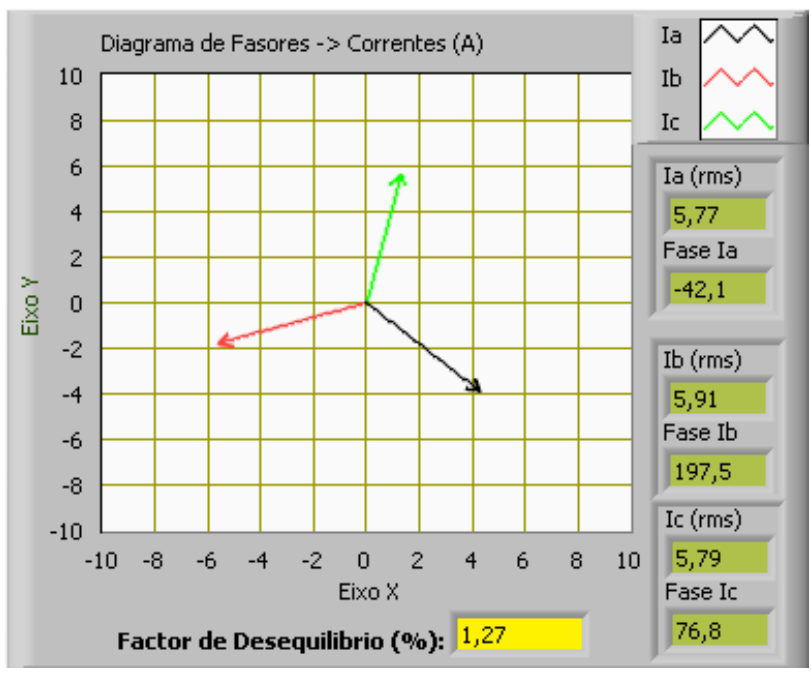

Fig. 10. Phasor diagram of the source currents when the Shunt Active Power Filter is not connected.

With the Power Quality Monitor, the data presented in tables II and III was compiled, tracing a profile of the electric system before the connection of the Shunt Active Filter. The first column of Table II shows the RMS values of the source currents and the system voltages, the second column indicates the peak-to-peak (PP) values, the third column shows the Total Harmonic Distortion (THD) and the last column indicates the Crest Factor (CF - mathematical ratio of the peak to RMS values of a waveform). There are slight discrepancies in the RMS values of the tables and the values displayed with the phasor diagram, but this is because these values were stored at different times. In Table III it is possible to see the different power components of the electric system for each phase, as well as the total 3-phase power components. The first line of Table III corresponds to the Active Power $(P)$, the second line shows the Reactive Power $(Q)$, the third line presents the Apparent Power $(S)$, the fourth line shows the Harmonic Power $(H)$, and the last line presents the Total Power Factor $(P F)$.

TABLE II. - Load profile before connecting the active filter.

\begin{tabular}{|c|c|c|c|c|}
\hline SIGNAL & RMS & PP & THD & CF \\
\hline$V_{a}$ & $76.7 \mathrm{~V}$ & $211 \mathrm{~V}$ & $3.1 \%$ & 1.4 \\
\hline$V_{b}$ & $77.4 \mathrm{~V}$ & $213 \mathrm{~V}$ & $2.7 \%$ & 1.4 \\
\hline$V_{c}$ & $76.8 \mathrm{~V}$ & $213 \mathrm{~V}$ & $2.3 \%$ & 1.4 \\
\hline$I_{a}$ & $5.7 \mathrm{~A}$ & $19.3 \mathrm{~A}$ & $20.1 \%$ & 1.7 \\
\hline$I_{b}$ & $5.9 \mathrm{~A}$ & $19.5 \mathrm{~A}$ & $20.0 \%$ & 1.7 \\
\hline$I_{c}$ & $5.9 \mathrm{~A}$ & $19.7 \mathrm{~A}$ & $20.2 \%$ & 1.7 \\
\hline$I_{n}$ & $0.4 \mathrm{~A}$ & $1.7 \mathrm{~A}$ & $188.0 \%$ & 2.6 \\
\hline
\end{tabular}

TABLE III. - Power profile before connecting the active filter.

\begin{tabular}{|c|c|c|c|c|}
\hline SIGNAL & Phase A & Phase B & Phase C & TOTAL \\
\hline$P$ & $325 \mathrm{~W}$ & $333 \mathrm{~W}$ & $329 \mathrm{~W}$ & $987 \mathrm{~W}$ \\
\hline$Q$ & $293 \mathrm{VAr}$ & $306 \mathrm{VAr}$ & $303 \mathrm{VAr}$ & $902 \mathrm{VAr}$ \\
\hline$S$ & $445 \mathrm{VA}$ & $460 \mathrm{VA}$ & $448 \mathrm{VA}$ & $1353 \mathrm{VA}$ \\
\hline$H$ & $85 \mathrm{VA}$ & $89 \mathrm{VA}$ & $87 \mathrm{VA}$ & $261 \mathrm{VA}$ \\
\hline$P F$ & 0.73 & 0.72 & 0.71 & --- \\
\hline
\end{tabular}


Once the Shunt Active Filter is connected and starts compensating the currents, it is possible to see that the power factor increases to an almost unitary value. The current unbalance becomes worse, increasing to $4.77 \%$ (as seen in Fig. 12), which is still an acceptable level. The source currents present some high frequency noise, because of the applied switching technique, however it is possible to conclude that there was an improvement in terms of THD and power factor. The losses of the active power filter are also very low, indicating that the introduction of the active filter improves the source currents without demanding a high level of energy to operate. This can be seen by comparing the values of the Active Power $(P)$ presented in tables III and V. Fig 11 shows the source currents and the system voltages when the Shunt Active Filter is compensating. Fig. 12 shows the phasor diagram of the source currents.

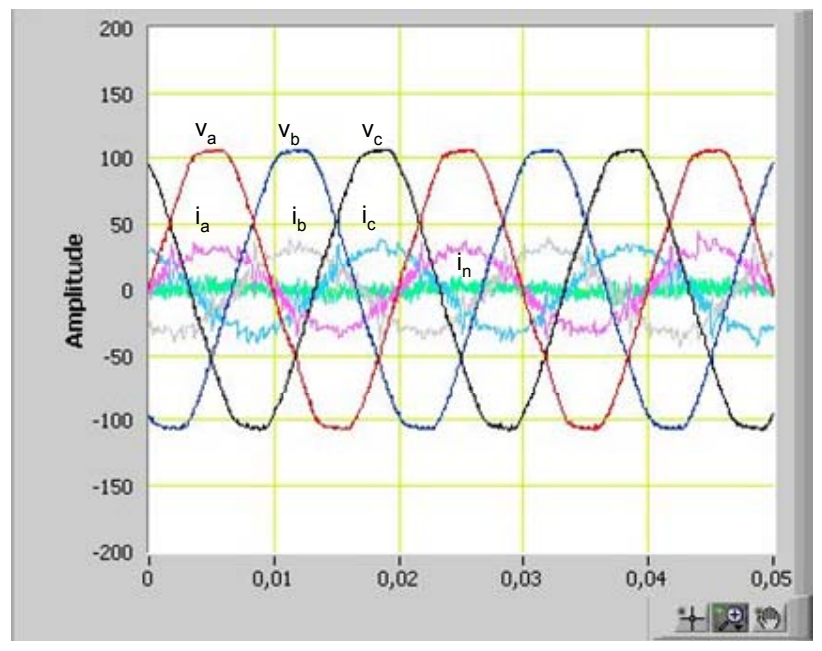

Fig. 11. System voltages and source currents waveforms when the Shunt Active Power Filter is compensating.

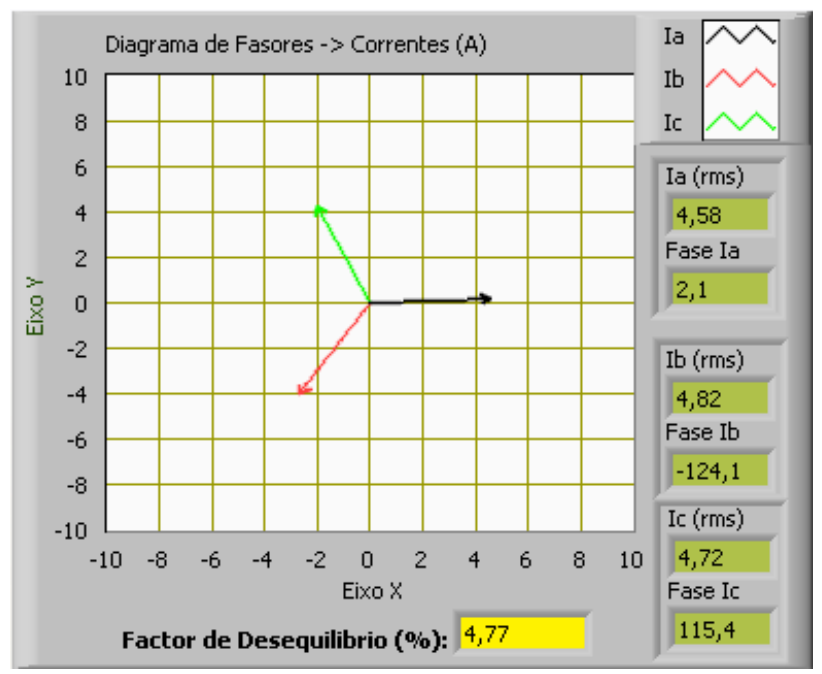

Fig. 12. Phasor diagram of the source currents when the Shunt Active Power Filter is compensating.

Tables IV and V presents the load profile when the Shunt Active Power Filter is working. It is possible to see that the reactive power is practically 0 and that the active power has only slightly increased, because of the losses at the inverter. The power factor is practically 1 at all phases.
TABLE IV. - Load profile after connecting the active filter.

\begin{tabular}{|c|c|c|c|c|}
\hline SIGNAL & RMS & PP & THD & CF \\
\hline$V_{a}$ & $76.9 \mathrm{~V}$ & $210 \mathrm{~V}$ & $2.9 \%$ & 1.4 \\
\hline$V_{b}$ & $77.3 \mathrm{~V}$ & $211 \mathrm{~V}$ & $2.6 \%$ & 1.4 \\
\hline$V_{c}$ & $76.5 \mathrm{~V}$ & $213 \mathrm{~V}$ & $2.3 \%$ & 1.4 \\
\hline$I_{a}$ & $4.6 \mathrm{~A}$ & $17 \mathrm{~A}$ & $14 \%$ & 1.9 \\
\hline$I_{b}$ & $4.7 \mathrm{~A}$ & $17.4 \mathrm{~A}$ & $12.6 \%$ & 1.8 \\
\hline$I_{c}$ & $4.7 \mathrm{~A}$ & $17.7 \mathrm{~A}$ & $12.5 \%$ & 1.8 \\
\hline$I_{n}$ & $0.4 \mathrm{~A}$ & $5 \mathrm{~A}$ & $60 \%$ & 6.2 \\
\hline
\end{tabular}

TABLE V. - Power profile after connecting the active filter.

\begin{tabular}{|c|c|c|c|c|}
\hline SIGNAL & Phase A & Phase B & Phase C & TOTAL \\
\hline$P$ & $345 \mathrm{~W}$ & $368 \mathrm{~W}$ & $356 \mathrm{~W}$ & $1069 \mathrm{~W}$ \\
\hline$Q$ & $-6 \mathrm{VAr}$ & $18 \mathrm{VAr}$ & $33 \mathrm{VAr}$ & $45 \mathrm{VAr}$ \\
\hline$S$ & $350 \mathrm{VA}$ & $373 \mathrm{VA}$ & $364 \mathrm{VA}$ & $1087 \mathrm{VA}$ \\
\hline$H$ & $55 \mathrm{VA}$ & $51 \mathrm{VA}$ & $52 \mathrm{VA}$ & $158 \mathrm{VA}$ \\
\hline$P F$ & 0.99 & 0.99 & 0.98 & --- \\
\hline
\end{tabular}

The second configuration, shown in Fig 13, consists of a case where there is a high level of unbalance, in addition to the power factor and the harmonic distortion. The Shunt Active Filter is capable of minimizing the neutral current as well as compensating power factor and current harmonics.

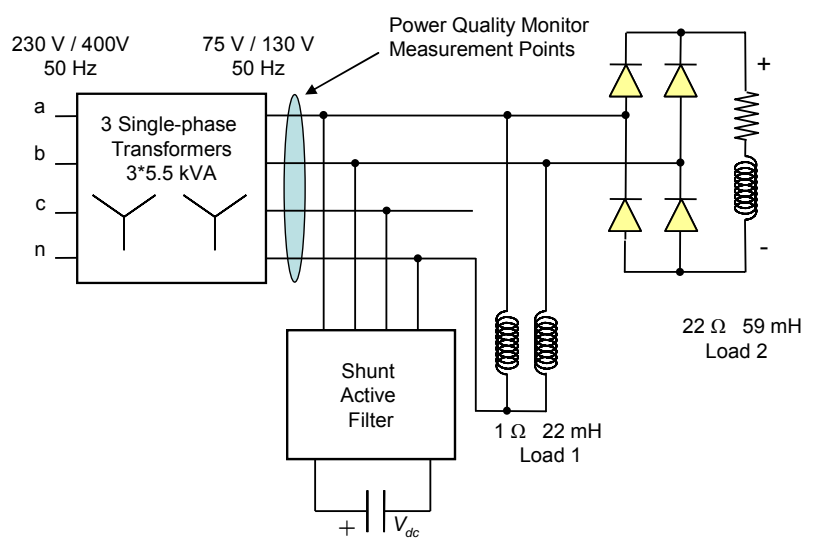

Fig. 13. Second configuration of the electric system.

Fig. 14 shows the display of the Power Quality Monitor, where it is possible to observe the system voltages and source currents of the electric system before the connection of the Shunt Active Power Filter. Fig. 15 presents the phasor diagram of the source currents, where it is possible to observe that the current at the phase $c$ is very close to zero. 


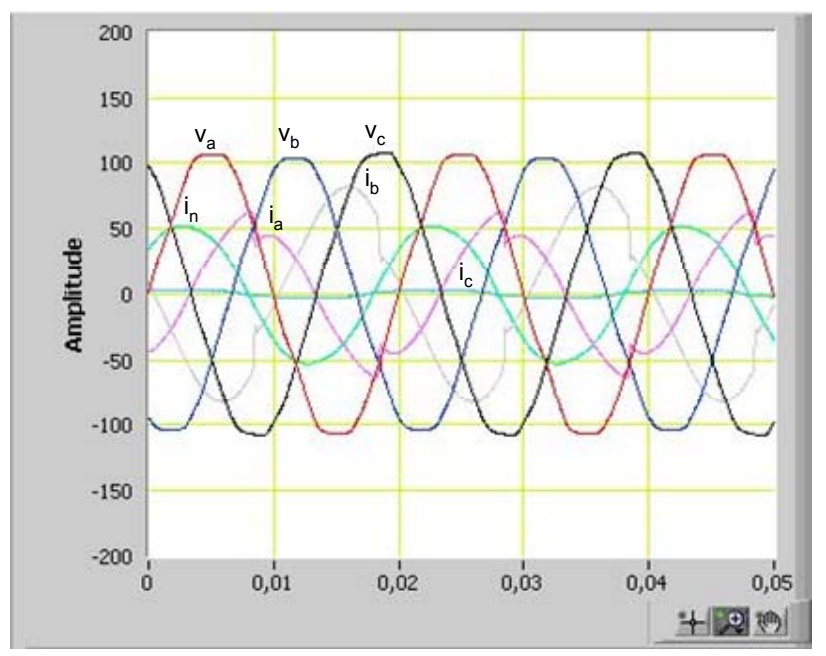

Fig. 14. System voltages and source currents waveforms when the Shunt Active Power Filter is not connected.

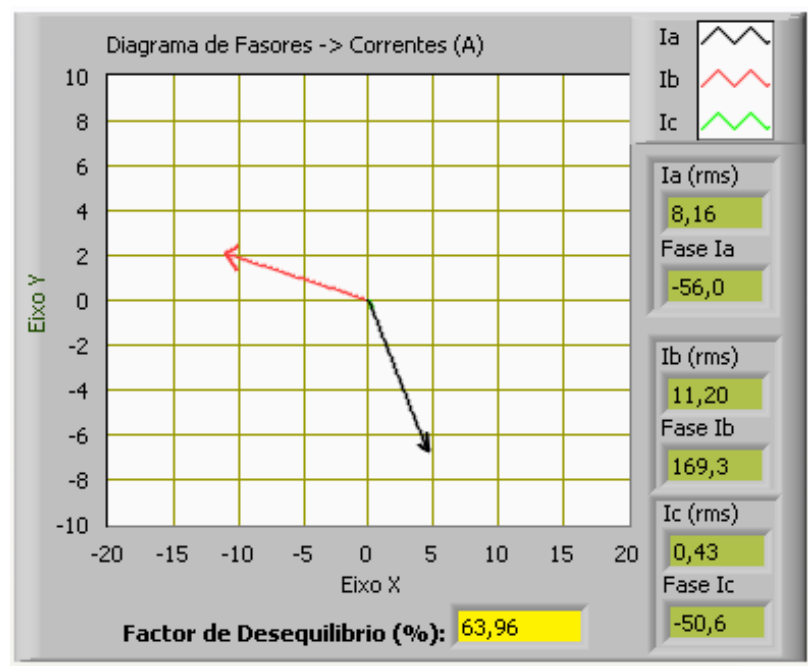

Fig. 15. Phasor diagram of the source currents when the Shunt Active Power Filter is not connected.

The following tables trace a profile of the voltages, currents and powers required by the loads. The reactive power is very high, especially on phase $b$, where the power factor is only 0.32 .

TABLE VI. - Load profile before connecting the active filter.

\begin{tabular}{|c|c|c|c|c|}
\hline SIGNAL & RMS & PP & THD & CF \\
\hline$V_{a}$ & $76.9 \mathrm{~V}$ & $215 \mathrm{~V}$ & $3.5 \%$ & 1.38 \\
\hline$V_{b}$ & $76.1 \mathrm{~V}$ & $210 \mathrm{~V}$ & $3.7 \%$ & 1.38 \\
\hline$V_{c}$ & $77.3 \mathrm{~V}$ & $219 \mathrm{~V}$ & $2.5 \%$ & 1.38 \\
\hline$I_{a}$ & $7.9 \mathrm{~A}$ & $25.6 \mathrm{~A}$ & $12.2 \%$ & 1.62 \\
\hline$I_{b}$ & $11.3 \mathrm{~A}$ & $33.21 \mathrm{~A}$ & $10.2 \%$ & 1.47 \\
\hline$I_{c}$ & $0.4 \mathrm{~A}$ & $1.47 \mathrm{~A}$ & $17.8 \%$ & 1.8 \\
\hline$I_{n}$ & $7.63 \mathrm{~A}$ & $21.27 \mathrm{~A}$ & $3.92 \%$ & 1.4 \\
\hline
\end{tabular}

TABLE VII. - Power profile before connecting the active filter.

\begin{tabular}{|c|c|c|c|c|}
\hline SIGNAL & Phase A & Phase B & Phase C & TOTAL \\
\hline$P$ & $350 \mathrm{~W}$ & $271 \mathrm{~W}$ & $0 \mathrm{~W}$ & $621 \mathrm{~W}$ \\
\hline$Q$ & $517 \mathrm{VAr}$ & $794 \mathrm{VAr}$ & $0 \mathrm{VAr}$ & $1311 \mathrm{VAr}$ \\
\hline$S$ & $629 \mathrm{VA}$ & $843 \mathrm{VA}$ & $0 \mathrm{VA}$ & $1472 \mathrm{VA}$ \\
\hline$H$ & $75 \mathrm{VA}$ & $85 \mathrm{VA}$ & $0 \mathrm{VA}$ & $160 \mathrm{VA}$ \\
\hline$P F$ & 0.556 & 0.321 & --- & --- \\
\hline
\end{tabular}

When the Shunt Active Filter compensates the currents, it is once again possible to see the improvements in terms of power factor and THD. The unbalance is highly reduced, decreasing from $63.96 \%$ to $8.35 \%$. Fig. 16 shows the system voltages and the source currents waveforms, and Fig 17 presents the phasor diagram, illustrating what was already stated. Tables VIII and IX show the profile of the voltages, source currents and powers at the source when the Shunt Active Power Filter is operating. Once again the reactive power becomes practically zero, and the amplitude of the currents decreases considerably. By comparing tables VII and IX it is possible to conclude that the losses at the inverter of the active filter are small.

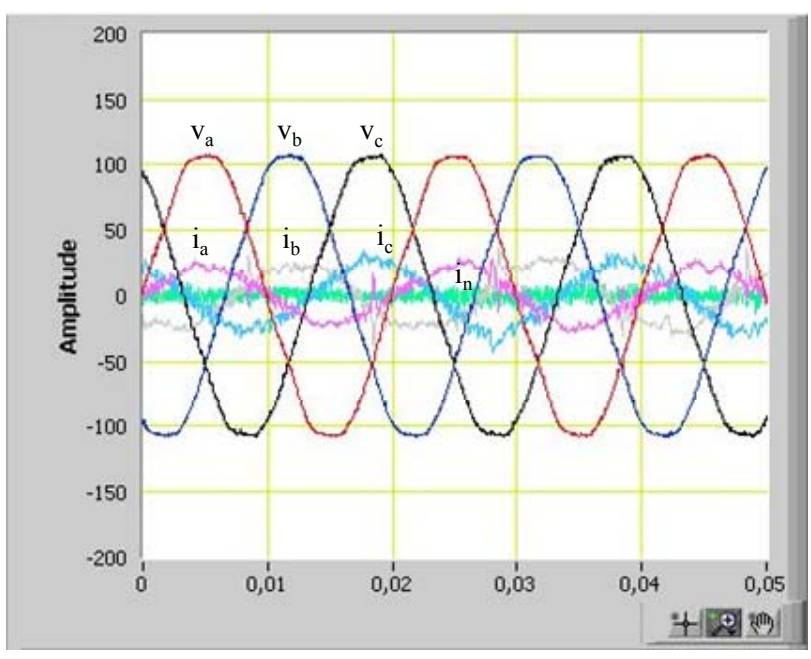

Fig. 16. System voltages and source currents waveforms when the Shunt Active Power Filter is compensating.

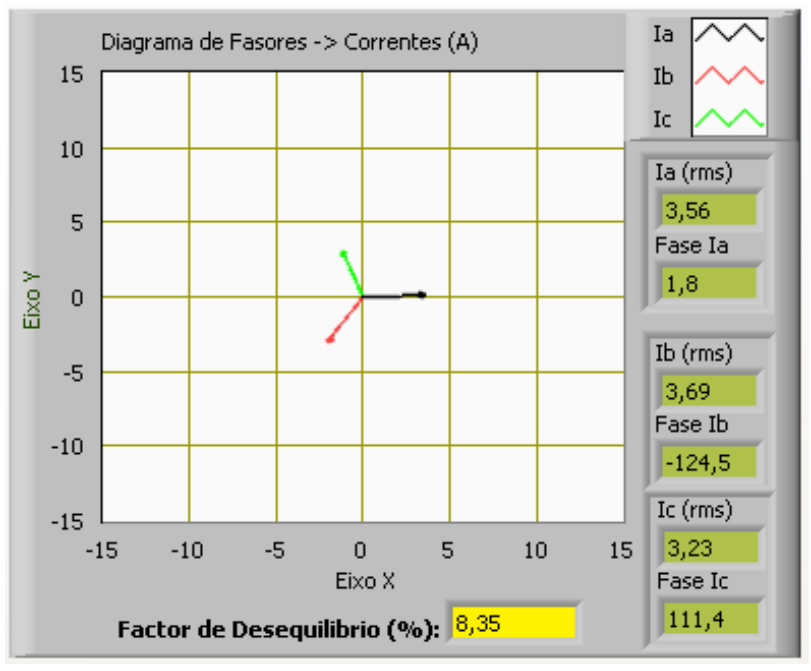

Fig. 17. Phasor diagram of the source currents when the Shunt Active Power Filter is compensating. 
TABLE VIII. - Load profile after connecting the active filter

\begin{tabular}{|c|c|c|c|c|}
\hline SIGNAL & RMS & PP & THD & CF \\
\hline$V_{a}$ & $77.1 \mathrm{~V}$ & $219 \mathrm{~V}$ & $3.2 \%$ & 1.38 \\
\hline$V_{b}$ & $77.1 \mathrm{~V}$ & $218 \mathrm{~V}$ & $3.1 \%$ & 1.38 \\
\hline$V_{c}$ & $77.2 \mathrm{~V}$ & $220 \mathrm{~V}$ & $3.4 \%$ & 1.38 \\
\hline$I_{a}$ & $3.11 \mathrm{~A}$ & $11.52 \mathrm{~A}$ & $14.9 \%$ & 2.18 \\
\hline$I_{b}$ & $3.76 \mathrm{~A}$ & $15.7 \mathrm{~A}$ & $15.7 \%$ & 2.1 \\
\hline$I_{c}$ & $3.71 \mathrm{~A}$ & $15.8 \mathrm{~A}$ & $10.1 \%$ & 2.05 \\
\hline$I_{n}$ & $0.25 \mathrm{~A}$ & $4.2 \mathrm{~A}$ & $353 \%$ & 9.65 \\
\hline
\end{tabular}

TABLE IX. - Power profile after connecting the active filter.

\begin{tabular}{|c|c|c|c|c|}
\hline SIGNAL & A & B & C & TOTAL \\
\hline$P$ & $263 \mathrm{~W}$ & $275 \mathrm{~W}$ & $241 \mathrm{~W}$ & $779 \mathrm{~W}$ \\
\hline$Q$ & $-11 \mathrm{VAr}$ & $20 \mathrm{VAr}$ & $30 \mathrm{VAr}$ & $39 \mathrm{VAr}$ \\
\hline$S$ & $265 \mathrm{VA}$ & $280 \mathrm{VA}$ & $250 \mathrm{VA}$ & $795 \mathrm{VA}$ \\
\hline$H$ & $41 \mathrm{VA}$ & $54 \mathrm{VA}$ & $33 \mathrm{VA}$ & $128 \mathrm{VA}$ \\
\hline$P F$ & 0.992 & 0.982 & 0.964 & \\
\hline
\end{tabular}

\section{Conclusions and Future Work}

This paper describes the main characteristics of a developed low cost Power Quality Monitor and the advantages of its utilization to perform Power Quality studies in a prototype of a Shunt Active Power Filter.

With the Power Quality Monitor it is easy to trace a profile of the electric system where a Shunt Active Filter may eventually be connected in the future, and then see the differences after the connection of this equipment in order to obtain a better perception of the improvements in terms of Power Quality and economical advantages.

In the future the developed Power Quality Monitor will be able to simultaneously read the source currents and the inverter currents in order to more effectively analyze the operation of the Shunt Active Power Filter.

\section{Acknowledgement}

This work was supported by FCT (Fundação para a Ciência e a Tecnologia), project funding POCTI/ESE/41170/2001 and POCTI/ESE/48242/2002. The authors are also grateful to PRIME (Programa de Incentivos à Modernização da Economia) for funding the Project SINUS. The author Luís F. C. Monteiro is grateful to Alban program for supporting his education project at the University of Minho.

\section{References}

[1] IEEE Standard 1159-1995, "Recommended Practice for Monitoring Electric Power Quality", 1995.

[2] EN 50160, "Caractéristiques de la Tension Fournie par les Réseaux Publics de Distribution”, 2001.

[3] José C. C. Costa , Ricardo L. Pregitzer, Tiago N. Sousa, José Batista, João L. Afonso, "A Case of Power Quality Assessment Using a Developed Power Quality Monitor", CEE'05 - International Conference on Electrical Engineering, Coimbra, 1012 Out. 2005.

[4] J. Batista, J. S. Martins, J. L. Afonso,"Low-Cost Power Quality Monitor Based on a PC", ISIE'2003 IEEE International Symposium on Industrial Electronics, R.J., Brasil, 9-11 Jun 2003, ISBN:07803-7912-8

[5] J. L. Afonso, C. Couto, J. S. Martins, "Active Filters with Control Based on the p-q Theory", IEEE Industrial Electronics Society Newsletter, vol. 47, $\mathrm{n}^{\mathrm{o}}$ 3, Sept. 2000, pp. 5-10.

[6] R. Pregitzer, J.C. Costa, Júlio S. Martins, J. L . Afonso, "Simulation and Implementation Results of a 3 Phase 4 Wire Shunt Active Power Filter", CDROM Proceedings of the ICHQP 2006 International Conference on Harmonics and Quality of Power, Cascais, Portugal, 1-5 October 2006.

[7] S. Buso; L. Malesani; P. Mattavelli; Comparison of Current Control Techniques for Active Filter Applications; IEEE Transactions on Industrial Electronics, vol. 45, Issue 5, Oct. 1998; Page(s):722 - 729 . 